\title{
A CASE OF ALKAPTONURIA WITH A STUDY OF ITS METABOLISM *
}

\author{
R. B. GIBSON, Ph.D. And C. P. HOWARD, M.D. \\ IOW A CITY
}

\section{REPORT OF CASE}

History.-A male, aged 44 years, entered the medical clinic in May, 1920, with symptoms and signs of a midbrain lesion, possibly due to a tuberculoma. He was almost completely aphasic and no history of his family antecedents or his previous medical condition could be elicited.

Examination.-The first two routine examinations of the urine revealed a slight reduction with Fehling's solution but no other abnormality was then noted. A day or two later, we were struck with the appearance of a specimen of urine because of its peculiar mahogany brown color. We were told that it belonged to our patient with the midbrain lesion and that it reduced Fehling's solution, which first appeared brownish black and later gave a reddish copper sediment. We naturally immediately suspected alkapton as the cause for the change. Our suspicions were further confirmed when it was found that the color of the freshly voided urine was the normal amber, which gradually deepened to dark mahogany brown on standing. Further special tests of the urine confirmed the presence of alkapton and the patient was transferred to the metabolism unit for more careful study.

Before giving the results of this study, let us briefly review the main points known about this anomaly of metabolism. Boedeker, ${ }^{1}$ in 1861 , first detected a reducing substance in the urine to which he gave the name "alkapton" (a bilingual word derived from alkali and katein, to absorb greedily) because of its behavior toward alkalies. In 1891, Wolkow and Baumann ${ }^{2}$ identified alkapton as homogentisic acid with an empirical formula of $\mathrm{C}_{8} \mathrm{H}_{8} \mathrm{O}_{4}$. Later, Baumann and Fraenkel, ${ }^{3}$ Osborne, ${ }^{4}$ and Neubauer and Flatow ${ }^{5}$ successfully synthetized it and proved its structural formula to be that of para-dioxyphenylacetic acid (hydroquinon-acetic acid)<smiles>O=C(O)C1CCCC(O)C1</smiles>

This substance can readily be separated from the urine by the addition of solid neutral lead acetate, the resultant dense precipitate filtered off,

\footnotetext{
* From the Medical Clinic and the Chemical Research Laboratory of the University Hospital of the State University of Iowa.

1. Boedeker, C.: Ann. d. Chem. u. Pharmakol. 117:98, 1861.

2. Wolkow, M., and Baumann, E.: Ztschr. f. physiol. Chem. 15:228, 1891.

3. Baumann, E., and Fraenkel, S.: Ztschr. f. physiol. Chem. 20:219, 1895.

4. Osborne, W. A.: J. Physiol. 29:13, 1903.

5. Neubauer, O. and Flatow, L.: Ztschr. f. physiol. Chem. 52:375, 1907.
} 
and the clear yellow filtrate allowed to stand in the cold when the crystals of lead homogentisate appear, which later can be purified into colorless crystals of homogentisic acid with a melting point of $146 \mathrm{C}$.

Qualitative Tests.-The urine on exposure to the air or on the addition of alkali turns brown or even black. It reduces copper solutions but does not yield to the fermentation test, does not reduce alkaline bismuth solutions and does not rotate polarized light. An ammoniacal solution of silver nitrate is quickly reduced by it in the cold. Lastly, when a dilute solution of ferric chlorid is added to the urine, drop by drop, a deep blue color appears for a moment, as each drop falls, until oxidation is complete.

Incidence.-It is a rare condition. Not more than seventy cases exist in the literature and only eleven have been reported from America. Barton Brune ${ }^{6}$ of Baltimore, in 1886, reported the first case in this couritry. Subsequently, cases were published by Marshall ${ }^{7}$ of Philadelphia, Ogden ${ }^{8}$ of Milwaukee, and Osler ${ }^{9}$ of Baltimore, etc., making a total of twelve, with ours. There is an unquestionable familial tendency, especially in the offspring of consanguineous marriages, according to A. E. Garrod. ${ }^{10}$ Though familial, it is not congenital, and no reports of parent and child being afflicted have ever appeared. Garrod's series of eleven cases occurred in four families in all of which the parents were first cousins. In its incidence, it shows a striking similarity to albinism. It is more common in males than females.

Symptomatology.-As a rule, there is no inconvenience experienced by the patient, except, possibly, the staining of the underclothes by the urine. Occasionally, there is dysuria. It is often not recognized until the patient submits to a life insurance examination and the applicant is rejected as a diabetic. One of Osler's patients had been treated for mild glycosuria by four prominent continental physicians, before consulting Osler. A more careful analysis of the urine by T. B. Futcher ${ }^{11}$ revealed the fact that the reducing substance was alkapton. Though usually constant, it may be intermittent, and absent for years at a time. A small proportion of the cases (twenty-four cases up to 1919) are associated with ochronosis or blackening of the cartilages and fibrous tissues and pigmentation of the skin. Alkaptonurics, with an associated ochronosis, may reveal during life pain, swelling and deformity of one or more of the larger joints of the extremities or of the small joints of the hands-a condition termed by Osler ochronotic arthritis. To

6. Brune, B.: Boston M. \& S. J. 115:621, 1886; 116:83, 1886.

7. Marshall, J.: Med. News, 50:35, 1887.

8. Ogden, H. V.: Ztschr. f. Physiol. Chem. 20:281, 1895.

9. Osler, W.: Lancet, 1:10, 1904.

10. Garrod, A. E.: Inborn Errors of Metabolism: 1909, London, p. 41.

11. Futcher, T. B.: New York M. J. 67:67, 1898. 
explain this condition, Albrecht ${ }^{12}$ considered that homogentisic acid, or one of its derivatives, combined with the chondromucoid or the chondroitin sulphuric acid of the cartilage to form the pigment.

In a few rare instances temporary alkaptonuria has been found in association with gastro-enteritis, gastric ulcer, pulmonary tuberculosis, peritoneal tuberculosis and diabetes. Falta and Langstein ${ }^{13}$ have shown that some patients with grave diabetes have less power of destroying homogentisic acid administered by mouth than have normal persons.

Pathogenesis.-It is a freak of metabolism, or as Garrod so well expresses it, "an inborn error of metabolism." The error consists in a failure to complete the catabolism of the aromatic fractions of the

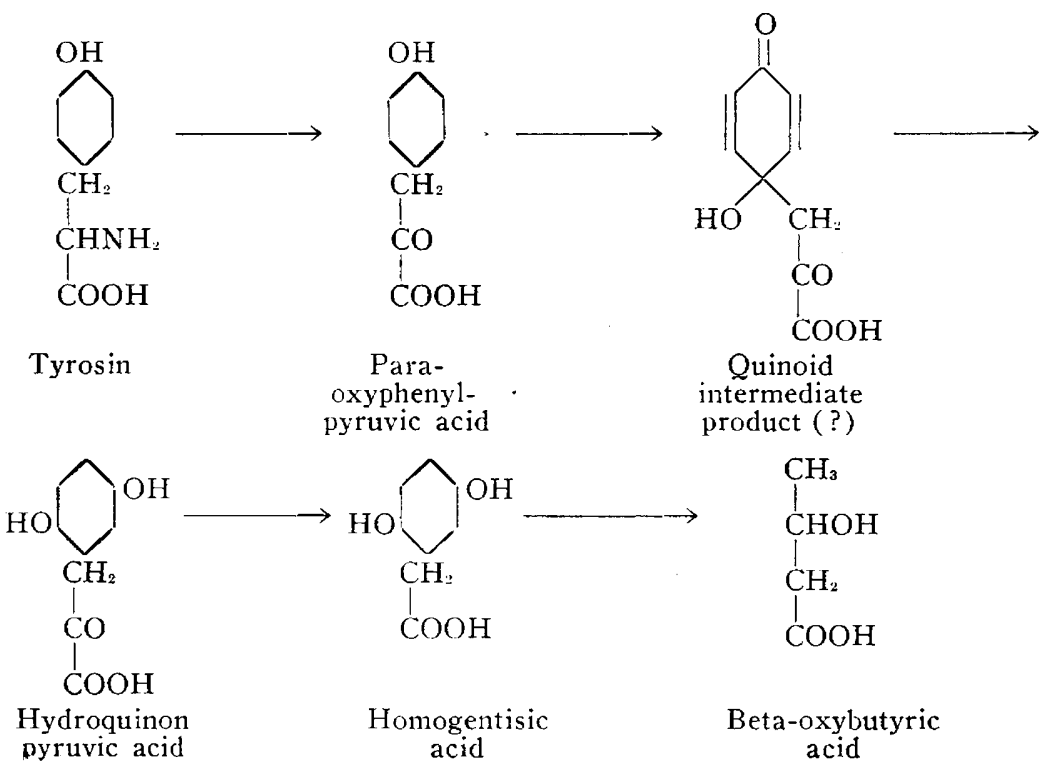

Fig. 1.-Scheme of the origin of homogentisic acid (adapted from Neubauer).

proteins, tyrosin and phenylalanin. The tyrosin and phenylalalin of both the food and tissue proteins are concerned. During fasting the output of homogentisic acid is diminished, but is not arrested. A diet rich in proteins greatly increase the output, and when tyrosin or phenylalanin is given by mouth to an alkaptonuric an almost corresponding quantity of homogentisic acid appears in the urine. On the other hand, these amino-acids, when taken by normal persons, are destroyed and the benzene ring broken up. The quantities or homogentisic acid excreted by different alkaptonurics are singularly uniform when the nature of

12. Albrecht, H.: Ztschr. f. Heilk. 23:366, 1902.

13. Falta, W., and Langstein, L.: Ztschr. f. physiol. Chem. 38:513, 1903. 
the diet and ages of the patients are allowed for. This amount varies from 3 to $6 \mathrm{gm}$. in twenty-four hours, though rarely $16 \mathrm{gm}$. and even $18 \mathrm{gm}$. have been found. Garrod states that there is reason to believe that the error is in all instances complete and maximal in degree. Wolkow and Baumann ${ }^{2}$ suggested that the change from tyrosin to alkapton might take place in the intestine under the influence of a rare specific microbe, but Garrod supports the view that the change occurs in the tissues after the absorption of the tyrosin rather than in the alimentary canal. Normally at least a part of the benzene ring may be broken up in the body, involving the production of betaoxybutyric acid; two of the carbon atoms of the latter are derived from the phenyl ring and two from the side chain, according to Wakeman and Dakin ${ }^{14}$ (Fig. 1); neither tyrosin nor phenylalanin yield glucose in the phloridzin diabetic $\operatorname{dog}$ as do some of the nonring-form amino-acids (Lusk). ${ }^{15}$

TABLE 1.-Determination of Homogentisic Acid

\begin{tabular}{|c|c|c|c|}
\hline \multirow[b]{2}{*}{ Day } & \multirow[b]{2}{*}{ Total N, Gm. } & \multicolumn{2}{|c|}{ Homogentisic Acid } \\
\hline & & Gm. & H-N Quot. \\
\hline $\begin{array}{l}6 / 11 / 20 \\
6 / 12 / 20 \\
6 / 13 / 20^{*}\end{array}$ & $\begin{array}{l}6.27 \\
7.84 \\
6.08\end{array}$ & $\begin{array}{l}3.77 \\
4.78 \\
6.27\end{array}$ & $\begin{array}{r}60 \\
61 \\
103\end{array}$ \\
\hline
\end{tabular}

* Two grams of tyrosin ingested.

In alkaptonurics, the conversion of tyrosin and phenylalanin into homogentisic acid is so complete that the ratio of homogentisic acid to the total nitrogen in the urine tends to be constant and the same for all cases (Garrod). The homogentisic acid amounts to 40 or 45 per cent of the total nitrogen figure.

Gross, ${ }^{16}$ in 1914, found that the serum of normal animals and man destroys homogentisic acid, probably producing acetone; this change is brought about by an active enzyme which seems to be absent in the alkaptonuric. Since our own observations have been made, Katsch ${ }^{17}$ has reported the case of a boy in whom he had earlier observed the disappearance of homogentisic acid from the urine during a starvation period. Subsequent study proved that the diminution of the alkapton condition was associated with ketone acidosis; at least the acidosis induced by a diet poor in carbohydrates reduced the $\mathrm{H}: \mathrm{N}$ quotient to 1.5. The coincident acetone elimination was greater than theoretically could be obtained from the aromatic amino-acids alone.

14. Wakeman, A. J., and Dakin, H. D.: J. Biol. Chem. 9:139, 1911.

15. Lusk, G.: The Science of Nutrition, Ed. 3, W. B. Saunders Co., Philadelphia, 1917, p. 196.

16. Gross, O.: Biochem. Ztschr. 61:165, 1914.

17. Katsch, G. : Deutsch. Arch. f. klin. Med. 127:210, 1918; 134:59, 1920. 


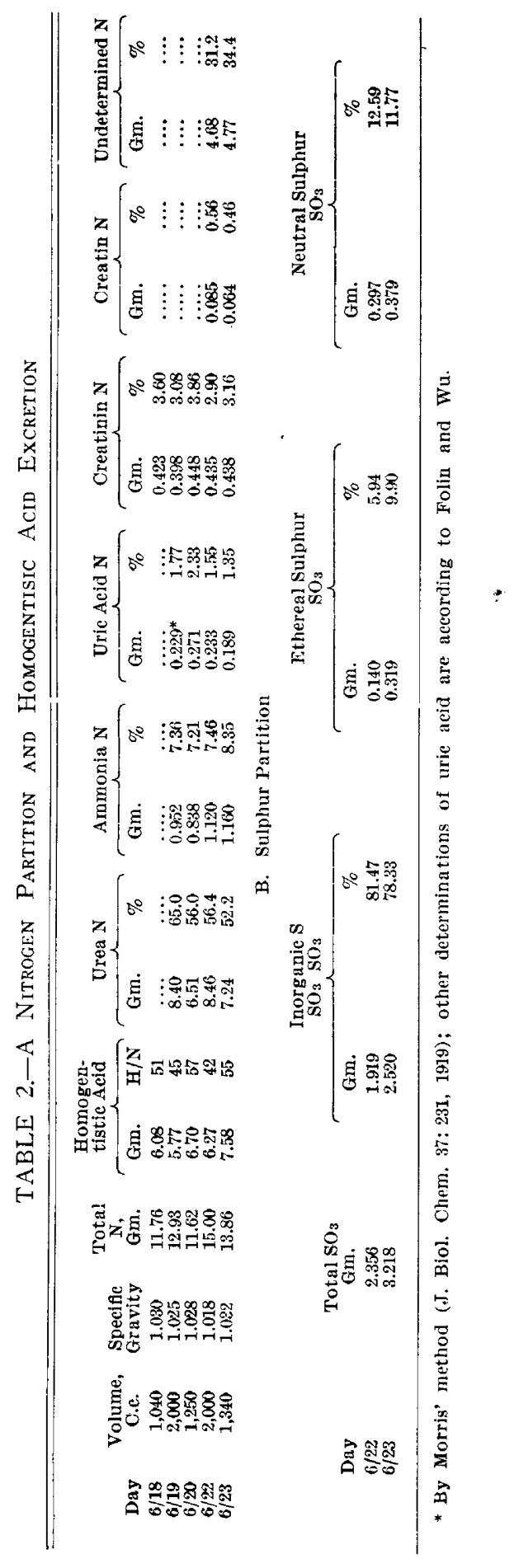


In order to prove metabolically the present case one of alkaptonuria, the patient was put on a constant diet ( $70 \mathrm{gm}$. protein, $83 \mathrm{gm}$. fat, and $253 \mathrm{gm}$. carbohydrate; no meat or soup); the homogentisic acid and the total nitrogen excretion were determined, affd the effects of tyrosin added to the diet observed. Homogentisic acid was determined by Garrod's modification of Baumann's method.

The homogentisic acid is higher in relation to the total nitrogen than is stated by Garrod, owing to the fact that milk was a principal constituent of the diet, and casein contains more of the aromatic aminoacids than do many of the common proteins. The characteristic increase in homogentisic acid is observed to follow the tyrosin ingestion. Subsequent determinations (Table 2) show a quotient of 42 to 57 , with an average for the five days of 50 ; at this time the patient was on a varying diet and the food intake was not controlled.

The distribution of the several nitrogenous constituents of the urine in alkaptonuria is said to remain normal (Lusk). ${ }^{15}$ Only by high elimination of the homogentisic acid is the ammonia increased (Schumm). ${ }^{18}$ Adler ${ }^{19}$ states that purine metabolism is not disturbed. Ravold and Warren ${ }^{20}$ found the urea below the average and the uric acid somewhat diminished. Interest in the sulphur metabolism was early directed to the possible conjugation of the homogentisic acid, but the acid was found to be free or combined as simple salts (Meyer). ${ }^{21}$

Certain difficulties are encountered in the determination of uric acid and creatinin by current methods in the presence of homogentisic acid. This is especially true of creatinin, which was finally determined after the removal of homogentisic acid with lead acetate. The silver lactate reagent of Folin and $\mathrm{Wu}^{22}$ was promptly reduced in the cold, a reaction which should serve to identify homogentisic acid as other reducing substances that are found in the urine do not behave in this way.

In our case we found a high ammonia nitrogen, low urea nitrogen, moderately high uric acid nitrogen figures, creatinuria, and high undetermined nitrogen. The sulphur excretion seems to have been essentially normal.

18. Schumm, O.: Muench. med. Wchnschr. 51:1599, 1904.

19. Adler, O.: Biochem. Ztschr. 21:5, 1909.

20. Ravold, A., and Warren, W. H. : J. Biol. Chem. 7:465, 1910.

21. Meyer, E.: Deutsch. Arch. f. klin. Med. 70:443, 1901.

22. Folin, O., and Wu, H.: J. Biol. Chem. 38:459, 1919. 